Forthcoming in Economic Inquiry.

\title{
Strategic Information Disclosure: The Case of Multi-Attribute Products with Heterogeneous Consumers*
}

\author{
V. Joseph Hotz \\ Duke University and NBER \\ Mo Xiao \\ University of Arizona
}

April 2010

\begin{abstract}
We examine the incentives for firms to voluntarily disclose otherwise private information about the quality attributes of their products. In particular, we focus on the case of differentiated products with multiple attributes and heterogeneous consumers. We show that there exist certain configurations of consumers' multi-dimensional preferences under which a firm, no matter whether producing a high- or low-quality product, may choose not to reveal the quality even with zero disclosure costs. The failure of information unraveling arises when providing consumers with more information results in more elastic demand, which triggers more intensive price competition and leads to lower prices and profits for competing firms. As a result, the equilibrium in which disclosure is voluntary may diverge from that in which disclosure is mandatory.
\end{abstract}

JEL: L15 (Information and Product Quality); L5 (Regulation and Industrial Policy) Keywords: Quality Disclosure; Multiple Attributes; Consumer Heterogeneity

*Hotz: Department of Economics, Duke University, Durham, NC 27708. hotz@econ.duke.edu. Xiao: Department of Economics, University of Arizona, Tucson, AZ 85721. mxiao@eller.arizona.edu. We thank Dan Ackerberg, Alberto Bernardo, Hongbin Cai, Harold Demsetz, Ginger Jin, Phillip Leslie, Bentley MacLeod, Robert Porter, John Riley, Michael Rothschild, Kenneth Sokoloff, Mark Stegeman, Gabor Virag, Bill Zame, participants of the IO Seminar at UCLA, and participants of the 2002 North American Econometric Society Summer Meeting and the 2002 Annual Conference of the European Association for Research in Industry Economics for comments on preliminary versions of this paper. All errors are ours. This research was funded by a grant from the National Institute for Child Health and Human Development (R01 HD035382). The authors are solely responsible for the contents of the paper. 


\section{Introduction}

As technological innovation constantly expands the dimensionality of the attribute space of products, the lack of information that consumers have about product quality has become of increasing concern for modern economies. However, one strand of the economics literature, initiated independently by Grossman (1981) and Milgrom (1981), suggests that this concern is misplaced. Both authors argue that strong incentives exist in markets for privately-informed firms voluntarily to disclose the quality of their products as long as there exists a verifiable disclosure mechanism with negligible costs. In equilibrium, firms' private information about the quality of their products would "unravel" and, as a result, a mandatory disclosure requirement would be redundant. ${ }^{1}$ In their models, there is little scope for firms to act strategically with respect to their disclosure decisions. In essence, high-quality firms, by distinguishing themselves from their lower-quality rivals, would always gain from revealing the true quality of their products, allowing them to charge consumers higher prices that reflect differences in quality. Only those with the lowest quality would choose not to reveal the quality of their products. However, their non-disclosure ends up being completely revealing as consumers correctly infer that a firm's failure of disclosure is always associated with the lowest-quality products.

If the above results hold, there are several phenomena that are somewhat difficult to explain. The first concerns the findings in a number of studies showing that consumers do respond to the imposition of mandatory disclosure requirements. For example, Jin and Leslie (2003) find that sales of restaurants became more sensitive to restaurants' hygiene quality after restaurants were required to post "grade cards" about their hygiene quality in Los Angeles County in the late 1990s. They further find that as a result of these grade cards the incidence of hospitalizations due to food-borne illnesses declined significantly. Similarly, Mathios (2000) finds that salad dressings with high fat content experienced large reductions in

\footnotetext{
${ }^{1}$ The logic of their result is as follows. If no firm discloses its product quality, consumers will be unable to distinguish between the highest-quality product and the lower-quality ones. Firms producing products with the highest quality will want to disclose their quality, because they will then be able to charge a higher price and achieve higher profits. Firms with the next highest quality product have the same incentive to distinguish themselves from the remaining firms. This process continues, so long as the benefits of disclosure outweigh the costs. In the limit when
} 
sales after the Nutritional Labeling and Education Act mandated all food products to carry standardized labels with information on a product's nutritional content.

Second, there is evidence that firms in some industries actively oppose the imposition of laws and regulations that require mandatory disclosure. For example, lobbying by the National Automobile Dealers Association in 1976 led to the abolishment of the Federal Trade Commission's mandatory inspection and disclosure rules on used-car dealers. In 1998, the National Restaurant Association strongly opposed the imposition of a requirement that all restaurants in Los Angeles County publicly display "grade cards" that revealed each restaurant's hygiene practices. $^{2}$ Finally, the National Hospital Association opposed a proposal in 2000 by the Clinton administration to impose mandatory reporting on hospitals of all fatal and other serious medical errors. ${ }^{3}$ If it is in the self-interest of firms - unless the firm produces the worst quality - to voluntarily reveal the quality of their products, why would they, or their industry representatives, expend resources to avoid mandatory disclosure requirements?

In this paper, we consider the robustness of the Grossman (1981) and Milgrom (1981) unraveling result. We consider the decisions of firms to voluntarily provide information about the quality of their products that would otherwise be unobserved by consumers. We assume that firms have access to a mechanism with which they can credibly disclose such information at zero cost. There are two features that distinguish our model from previous work. First, we allow products to have multiple attributes. Second, we assume that there is heterogeneity across consumers in their preferences over these attributes. Following the literatures on product differentiation and hedonic pricing, we consider a model in which products are both horizontally and vertically differentiated, where quality is the vertical attribute. We show that a firm producing a high-quality product may actually benefit, rather than lose, from consumers'

\footnotetext{
disclosure costs are zero, the situation in which firms withhold private information about product quality "unravels."

${ }^{2}$ See Food Council News, Vol. 5, Issue 1, January 2002. The National Restaurant Association stated that the "rating initiatives reduce complex issues to a score or letter based on subjective decisions by individual inspectors." The industry maintained that if an establishment is good enough to pass a hygiene inspection, having to post ratings would constitute overkill.

${ }^{3}$ See CNN News, February 22, 2000. "A culture of silence" in the medical profession can be traced back to 1930s, when physicians were advised to "keep a cautious tongue" regarding medical errors (Gallagher et al., 2002).
} 
ignorance about product quality. This can arise if, as a result of revealing it to be the seller of a highquality product, its competitor's products become more substitutable and consumers' demands become more elastic. Whether the demand for these products become more elastic depends on the distribution of consumers' preferences over both the horizontal and vertical attributes of products. If demand does becomes more elastic, disclosure will lead to more intense price competition between rival firms, causing prices and profits to fall for all firms. Alternatively, if this firm produces a low-quality product and reveals the fact to consumers, it also can suffer from lower profits as some consumers opt out of the market. Thus, this firm, regardless of whether it produces a high- or low-quality product, can find it in its interest to not disclose the quality of its product.

We note that there is a substantial literature that considers variants of the Grossman and Milgrom models. Okuno-Fujiwara et al. (1990) derive sufficient conditions for complete revelation of all private information in equilibrium in a fairly general model. Researchers also have investigated certain types of disclosure costs (Jovanovic, 1982; Verrecchia, 1983; Dye, 1986), costs of information acquisition by sellers (Matthews and Postlewaite, 1985; Farrell, 1986; Shavell, 1994), consumers' limited understanding of sellers' disclosure (Fishman and Hagerty, 2003), consumers' uncertainty of the existence of information (Dye and Sridhar 1995; Stivers, 2004), and alternative market structures (Cheong and Kim, 2004; Board, 2009; Levin, Peck, and Ye, 2009). In these extensions, the failure to obtain voluntary disclosure from sellers hinges on some form of "costs" associated with disclosure. ${ }^{4}$ The basic conclusion that complete voluntary disclosure will occur in equilibrium continues to hold as long as these disclosure costs are zero. Furthermore, in the absence of such costs, these models lead to a rather strong conclusion, namely, that regulatory policies that mandate product quality disclosure are, at best, redundant. As a result, the only potential form of government intervention that would benefit consumers would be in the form of providing low-cost and credible mechanisms for the disclosure of the quality of products. ${ }^{5}$ In contrast to the pre-

\footnotetext{
${ }^{4}$ Exceptions are Fishman and Hagerty (2003) and Board (2009).

${ }^{5}$ This claim hinges on maintaining the assumption that firms are perfectly informed about the quality of their own and their competitors' products. Firms, themselves, may benefit from mandatory information disclosure requirement to the extent that they are not perfectly informed.
} 
vious literature, we establish a set of conditions under which an equilibrium may exist in which firms do not have an incentive voluntarily to disclose the quality of their product and there may be a benefit to consumers of governments mandating product quality disclosure even if disclosure costs are zero.

Our results are closely related to the literature on firms' decisions about whether to differentiate their products from those of rivals. The literature on product differentiation notes the inherent tension between the benefits to a firm from differentiating its products from those of its competitors and the desire to produce a product that is attractive to a large consumer base. ${ }^{6}$ We show that this same tension arises in firms' disclosure decisions about the quality of these products. While we assume that the attributes of products are exogenously given, we show that the nature of firms' disclosure decisions about the quality of their product is very similar to firms' decisions about optimal product differentiation when some or all attributes are endogenously chosen.

The paper most closely related to ours is Board (2009), which considers a duopoly model with an outside option. In Board's model, a firm also needs to balance the incentives to alleviate competition with its higher-quality rivals and the outside option, which has the utility of zero. This feature implies that the profit function of the lower-quality firm is non-monotonic in its quality. Our model differs from Board's in that we provide an alternative mechanism to underlay this non-monotonicity in the firm's profit function. We focus on the head-to-head rivalry of the duopoly and do not depend on the existence of an outside option. We do so by allowing consumers to have heterogeneous tastes for not only over quality but also over location, i.e., we allow for horizontal as well as vertical product differentiation. ${ }^{7}$ Allowing for both of these dimensions and heterogeneity in consumer tastes over them is important for several reasons. First, our approach embeds the assessment of disclosure incentives within the broader literature on prod-

\footnotetext{
${ }^{6}$ See Tirole (1994, Chapter 7) for an overview of the product differentiation literature. Most studies consider firms' differentiation decisions for products that are horizontally or vertically differentiated. See Hotelling (1929), d'Aspremont, Gabszewicz, and Thisse (1979), and Neven (1985) for the former case and Mussa and Rosen (1978) and Gabszewicz and Thisse (1979) for the latter case. In a paper most closely related to our model, Neven and Thisse (1990) examine firms' differentiation decisions for products that have both horizontal and vertical dimensions.

${ }^{7}$ Levin, Peck, and Ye (2005) have a similar mechanism in their model, but quality unraveling does not break down with disclosure cost and they focus on welfare analysis of costly disclosure under alternative market structures.
} 
uct differentiation, where products are viewed as bundles of multiple characteristics. ${ }^{8}$ Second, allowing firms' disclosure incentives to depend on the distribution of consumers' preferences over both the horizontal and vertical attributes of products provides potentially verifiable conditions for when, in the absence of regulation, less-than-complete disclosure can occur and, thus, provides more explicit and positive guidance for those situations in which mandatory product disclosure may be needed to reduce anticompetitive firm behavior.

The results of this paper also are related to the literature on informative advertising. For example, Grossman and Shapiro (1984) consider the strategic effect of firms using advertising to provide truthful information about their location. They note that firms in an oligopoly setting may actually benefit from higher advertising costs and may even seek to raise such costs themselves. This is because higher advertising costs can reduce the amount of advertising done in a market and leave consumers with less information to act upon when making their product choices. Less informed consumers will be less sensitive to prices across products and, as a result, firms can raise prices and achieve higher profits. It has sometimes been argued that this benefit of making advertising more costly is what has motivated professional organizations, such as the American Medical Association or the American Bar Association, to seek limitations on the amount of advertising done by its membership (Peters, 1984). This incentive for strategic advertising is similar to the one that we argue may discourage firms from voluntarily disclosing the quality of their products. ${ }^{9}$

The remainder of the paper is organized as follows. In section 2, we develop a duopoly model in which firms strategically choose to disclose the quality attribute of their products. In section 3 , we provide an intuitive explanation of how the disclosure of the quality of products can affect demand elasticities and lead to more intense price competition among competing firms in a market. Section 4 offers concluding

\footnotetext{
${ }^{8}$ The work of Becker (1965), Lancaster (1966), Muth (1966), Rosen (1974), and Gorman (1980) views all goods and services as bundles of characteristics. Tastes are plausibly heterogeneous over these attributes and, thus, over the bundles. These two features - products viewed as bundles of characteristics and consumer heterogeneity-are the key elements of the literature on product differentiation and hedonic pricing.

${ }^{9}$ Anderson and Renault (2006) offer an interesting comparison, in which they study firms' strategic choices of disclosing horizontal attributes while the vertical attributes are known. The essence of their work is also that the prod-
} 
remarks. Longer proofs are relegated to the Appendix.

\section{Model}

\section{$2.1 \quad$ Set $U p$}

We consider a duopoly model in which two firms sell products with two attributes. Each firm, firm $A$ and firm $B$, is endowed with a product $Y_{j}$, where $j=A, B$. These products differ across firms in their horizontal attribute, location (denoted by $L$ ), ${ }^{10}$ and in their vertical attribute, the quality of their product (denoted by $Q)$, so that $Y_{j}=\left(L_{j}, Q_{j}\right)$. We assume that these attributes are exogenously given and cannot be altered and that firms produce their products with zero production costs. ${ }^{11}$ With respect to the vertical attribute, either firm can produce a high-quality product $\left(q_{h}\right)$, or a low-quality one $\left(q_{l}\right)$, but not both. We denote the difference between these two types of product qualities by $\Delta$ where $\Delta=q_{h}-q_{l}>0$. Both firms are assumed to produce $q_{h}$ or $q_{l}$ with equal probabilities.

With respect to the horizontal attribute, firms are located vis-à-vis consumers at the end points of a Linear City, displayed in Figure 1. Let $L_{j}$ denote the location of firm $j$ in the linear city. Firm $A$ 's location is fixed at $L_{A}=0$ and firm $B$ 's at $L_{B}=1$. Consumers are uniformly distributed along the Linear City in Figure 1, where $X_{i}\left(0 \leq X_{i} \leq 1\right)$ denotes the $i^{\text {th }}$ consumer's location; thus, consumers differ with respect to their proximity to the two firms. We denote the distance of the $i^{\text {th }}$ consumer from the $j^{\text {th }}$ product as $D_{i j}=$ $\left|L_{j}-X_{i}\right|$

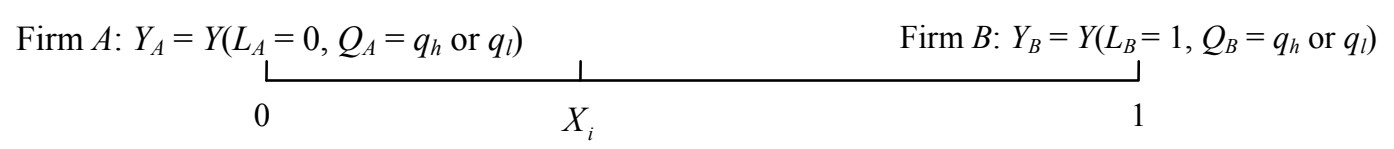

Figure 1: The Linear City

Following the standard formulation of the discrete choice model in the context of differentiated

\footnotetext{
uct differentiation incentives in a multi-attribute product space may block complete voluntary disclosure.

${ }^{10}$ Herein, location represents the horizontal attribute of a product. Horizontal attributes are those for which consumers have different preferences at the same prices, e.g., the color of an automobile.

${ }^{11}$ We make this assumption so that consumer beliefs do not vary with prices: prices do not depend on the value of any undisclosed quality and profit maximizing prices have no signaling roles. Daughety and Reingamum (2008) discuss disclosure through a credible agency and signaling via producer actions in a unified model.
} 
products, ${ }^{12}$ we assume that consumers face a set of three mutually exhaustive alternatives from which they must choose: product $Y_{A}$, product $Y_{B}$, and an outside alternative, $Y_{0}$. In evaluating the "genuine" products - products $A$ and $B$ - consumers consider a product's price, $P_{j}$; the transportation costs, $\lambda D_{i j}$, where $\lambda$ is the per-unit distance cost to consumers; ${ }^{13}$ and the consumer's perception of its quality, $E_{\Omega}\left(Q_{j}\right) \equiv E\left(Q_{j} \mid \Omega\right)$, i.e., the consumers' expectation of the quality of product $j$, conditional on the information, $\Omega$, about the quality of products in the market that is disclosed to them by either seller.

We allow heterogeneity in consumer preferences with respect to a product's vertical attribute. In particular, we assume there are two types of consumers - "quality-satisficers" and "quality-lovers" - that differ in their valuation of a product's amount of expected quality. ${ }^{14}$ The $i^{\text {th }}$ consumer, depending on her type, derives expected utility ${ }^{15}$ from product $j(j=A$ or $B)$ according to the following utility functions:

For quality-satisficers: $U_{i j}\left(D_{i j}, E_{\Omega}\left(Q_{j}\right), P_{j}\right) \equiv V+\theta_{0} I\left(E_{\Omega}\left(Q_{j}\right) \geq q_{a}\right)-\lambda D_{i j}-P_{j}$

For quality-lovers: $U_{i j}\left(D_{i j}, E_{\Omega}\left(Q_{j}\right), P_{j}\right) \equiv \theta\left(E_{\Omega}\left(Q_{j}\right)-q_{l}\right)+\theta_{0} I\left(E_{\Omega}\left(Q_{j}\right) \geq q_{a}\right)-\lambda D_{i j}-P_{j}$

Note $I($.$) is an indicator function to capture a "quality assurance" effect once the expected quality is$ above a certain threshold. In the above specification, consumers' preferences over the quality of a product consist of two components. First, quality-satisficers receive at least a fixed amount of utility, $V$, for purchasing a product at any quality level. And, since we assume $V<\lambda$, the willingness of quality-satisficers to participate in the market is bounded, so that some or all of this type of consumers will opt out of the market if firms charge too high a price for their products. In contrast, quality-lovers receive no utility from a low-quality product but a utility equal to $\theta\left(E_{\Omega}\left(Q_{j}\right)-q_{l}\right)$ for a product with quality above $q_{l}$.

\footnotetext{
${ }^{12}$ See Anderson, de Palma and Thisse (2001) for a summary of these models.

${ }^{13}$ In essence, $\lambda$ measures the spread of consumer heterogeneity over the horizontal attribute. The greater the value of $\lambda$, the harder it is for consumers to travel from one end of the city to the other.

${ }^{14}$ Satisficing is a word coined by Herbert Simon (1957), referring a decision-making strategy that attempts to meet criteria for adequacy.

${ }^{15}$ We evaluate utilities of consumers when they make their (possibly uninformed) decisions so all "utilities" we refer to are expected utilities.
} 
Thus, the utility of quality-lovers is monotonically increasing in the expected quality of a product. Second, all consumers, quality-satisficers and quality-lovers, receive a boost in utility, $\theta_{0}$, from purchasing a product which has a perceived quality higher than or equal to $q_{a}$, where $q_{a} \in\left(q_{l},\left(q_{h}+q_{l}\right) / 2\right)$. We assume that $\theta_{0} \geq 2 \lambda .{ }^{16}$ This feature of the utility functions ensures that firm $A$ and $B$ engage in direct competition with each other in the markets for both quality-satisficers and quality-lovers when the expected qualities of both products are sufficiently high.

To summarize, both types of consumers - quality-satisficers and quality-lovers - care about whether the perceived quality of a product is above a certain level, although we assume that there are limits to how much utility quality-satisficers get out of consuming quality, while quality-lovers continue to value incremental quality above this threshold. For example, "satisficed" restaurant patrons, while not preoccupied with the hygiene used in the preparation of their food, still get utility from knowing that the restaurant of their choice is sufficiently sanitary so as to minimize their risk of getting food poisoning. In contrast, the utility of quality-loving restaurant patrons continues to rise as a restaurant practices more and more stringent hygiene in its preparation of meals.

Finally, we assume that the outside alternative is available to consumers with zero price and no transportation costs, and we normalize the utility associated with this outside alternative to 0 , i.e. $U_{i O} \equiv 0$. Consumers' purchase decisions depend on a comparison of the utility from participating in the market and that from the outside option. The presence of the outside alternative implies that some or all consumers may "opt out" of the market for $Y_{A}$ or $Y_{B}$ if consuming either of these products would produce negative utility or, conversely, that a consumer will purchase product $j$ only if

$$
U_{i j}\left(D_{i j}, E_{\Omega}\left(Q_{j}\right), P_{j}\right)>0, j=A, B \text {. }
$$

Assuming the market participation constraint in (3) is the standard way for creating some discipline on the

\footnotetext{
${ }^{16}$ It can be easily shown that when both products are perceived to be of quality greater than $q_{a}$, the assumption $\theta_{0} \geq$ $2 \lambda$ ensures that the marginal consumer who is indifferent between choosing product $A$ or $B$ will receive a utility greater than 0. Tirole (1994), in discussing spatial competition (Chapter 7.1), makes a similar assumption to ensure that consumers' surplus from the goods is sufficiently large to induce the two firms to engage in direct competition.
} 
pricing and quality-disclosing decisions of sellers. In essence, the possibility that consumers can either purchase or produce other goods is a natural way to avoid the situation of consumers being "captive" to certain markets, i.e., being forced to purchase one product or the other. Allowing for an outside option creates a potential (or actual) "punishment" to firms for disclosing that their products are low quality. For algebraic simplicity, we restrict consumer preferences so that the low-quality product provides a level of utility at or below that for the outside option for quality-lovers. ${ }^{17}$ Consider, for example, the market for child care. ${ }^{18}$ A feature of such markets is the heterogeneity in the quality of market-based child care centers that parents might use. A key alternative to market-based forms of care is the outside option of parents, themselves, providing for the care of their children. Parents do elect to care for their children instead of using low-quality child care centers and, consistent with our model, this decision is often affected by such factors as the costs of transporting their children to and from such centers.

Consumer heterogeneity is characterized by the joint distribution of consumers' locations and tastes for product quality, $\operatorname{Pr}\left(X_{i}, \theta_{i}\right)$. At the extreme, the distribution of consumers' locations and tastes for quality may be uncorrelated, i.e., $\operatorname{Pr}\left(X_{i}, \theta_{i}\right)=\operatorname{Pr}\left(X_{i}\right) \operatorname{Pr}\left(\theta_{i}\right)$. Alternatively, the distribution of consumers' locations and tastes for quality may be correlated. To characterize this joint distribution, we assume that consumers' preferences for quality, conditional on their location, are distributed as follows:

$$
\begin{aligned}
& \operatorname{Pr}\left(\theta_{i}=0 \mid X_{i}\right)=-\beta X_{i}+\frac{1+\beta}{2}, \\
& \operatorname{Pr}\left(\theta_{i}=\theta \mid X_{i}\right)=\beta X_{i}+\frac{1-\beta}{2},
\end{aligned}
$$

where the parameter, $\beta$, measures the degree of correlation in consumer preferences over the horizontal

\footnotetext{
${ }^{17}$ The assumption $q_{a} \in\left(q_{l},\left(q_{h}+q_{l}\right) / 2\right)$ greatly simplifies algebra in deriving Proposition 1 presented below. It does, however, rule out the possibility that quality lovers receive less utility from the outside option than from the low-quality product, $q_{l}$. While we do not formally prove that incomplete disclosure can occur in the latter situation, it is clear that the seller of a low-quality product can lose market share to the outside option in the lovers market by disclosing the quality of its product. This is because some quality lovers - in particular, those who reside further from the firm selling the low-quality product - may choose the outside option over the low-quality product as a result of this disclosure. That is, a firm selling a low-quality product will still be "punished" by disclosure in much the same way as in the model that maintains the above restriction.

${ }^{18}$ See Currie and Blau (2006) for a discussion of this market and the role that quality heterogeneity plays in parental child care decisions.
} 
and vertical attributes and we assume that $\beta \in[0,1] .{ }^{19}$ Consider the following two extreme cases:

Case I: $\beta=0 \Rightarrow \operatorname{Pr}\left(\theta_{i}=0 \mid X_{i}\right)=\frac{1}{2}$ and $\operatorname{Pr}\left(\theta_{i}=\theta \mid X_{i}\right)=\frac{1}{2}$

Case II: $\beta=1 \Rightarrow \operatorname{Pr}\left(\theta_{i}=0 \mid X_{i}\right)=1-X_{i}$ and $\operatorname{Pr}\left(\theta_{i}=\theta \mid X_{i}\right)=X_{i}$

In Case I, consumers' locations and tastes for quality are uncorrelated, so that quality-satisficers and quality-lovers are equally likely to be located at any point along the Linear City. In Case II, however, qualitylovers are more likely to live close to firm $B$ (located at $L_{B}=1$ ), while quality-satisficers are more likely to live close to firm $A$ (located at $L_{A}=0$ ). Case II, for example, characterizes the situation where firm $B$ is located in the upscale suburb of a city where consumers have a greater appreciation for quality than do residents who reside in the inner city close to firm $A .{ }^{20}$ As $\beta$ increases from 0 to 1 , the two groups of consumers become further geographically segregated with respect to their tastes. That is, $\beta$ characterizes the degree of consumer segregation with respect to the horizontal and vertical attributes.

To complete the setup, we need to characterize what consumers and firms know and do not know about the product attributes and the distribution of consumer locations and tastes for quality. We assume all consumers know their own preferences over quality, their own locations, and the locations of firms. Furthermore, consumers know the values of the parameters $\theta_{0}, \theta, \Delta, \lambda$, and $\beta$. As a result, consumers know how they are distributed with respect to their tastes for quality, i.e., they know the conditional probabilities in (4) and (5). Consumers are assumed not to know, a priori, the quality of either firm's product, at least not without any disclosure. However, they do know the distribution of quality levels in the market. ${ }^{21}$ With this information, consumers can form an ex-ante expectation about the undisclosed quality of each product, that is, $E_{\Omega=\varnothing}\left(Q_{A}\right)=E_{\Omega=\varnothing}\left(Q_{B}\right)=\left(q_{h}+q_{l}\right) / 2$. If firms provide consumers with any additional

\footnotetext{
${ }^{19}$ Note that all of our results go through if we allow for the possibility that $\beta \in[-1,1]$. This is because the two firms are identical ex-ante so that by simply reversing the locations of the two firms in Figure 1 we cover the case where $-1 \leq \beta \leq 0$. In an earlier working paper version (Hotz and Xiao, 2002), in which we have a low-quality firm and a high-quality one, we allow $\beta \in[-1,1]$ to allow the relationship between $X$ and $\theta$ to vary from negative to positive.

${ }^{20}$ This segregation can be a result of buyer-seller sorting, something which is not considered in this paper.

${ }^{21}$ That is, consumers know that four possible combinations of quality across the two firms can be offered, i.e., $\left(Q_{A}=\right.$ $\left.q_{h}, Q_{B}=q_{l}\right),\left(Q_{A}=q_{l}, Q_{B}=q_{l}\right),\left(Q_{A}=q_{l}, Q_{B}=q_{h}\right)$, and $\left(Q_{A}=q_{h}, Q_{B}=q_{h}\right)$, and, given their knowledge of the prob-
} 
information about product quality, consumers will update their beliefs using Bayes' rule. Finally, we assume that firms, besides having all of the information consumers possess, know the quality of their own products and that of their rivals. We make the latter assumption for two reasons. First, in many industries, firms do hire expert services and/or use superior technology to test rival products in order to learn about their quality and the incentives for firms to acquire such information about their rivals may exceed that of individual consumers. Second, and more important, we maintain this assumption to focus our model on the role that differential information between sellers and consumers, rather than among sellers, plays in disclosure decisions. ${ }^{22}$

\subsection{Disclosure Technology and Game Structure}

We assume that there exists a truthful and costless disclosure mechanism for sellers to disclose the quality dimension of their products. For example, there may be a non-profit certification agency offering free services to firms seeking disclosure. ${ }^{23}$ For example, the U.S. Food and Drug Administration (FDA) provides what amounts to certification, free of charge, of certain products ranging from bottled water to manufacturers of clinical diagnostic products that measure total cholesterol. Similarly, Good Housekeeping magazine will provide and publicize its Good Housekeeping Seal of Approval for products it deems to be of high quality. In our model, either firm can use this mechanism to credibly convey to consumers the quality of its product no matter whether it produces a high- or low-quality product.

To characterize the timing of firm decisions, we adopt a two-stage dynamic game. In the first stage, firms decide on disclosure simultaneously. In the second stage, firms engage in Bertrand competition to maximize profits and consumers choose which product to purchase to maximize utility. Consumers' valuations of products are conditional on product prices and what they have inferred about the quality of these products from what firms have disclosed about their products.

abilities, they know the probabilities with which these combinations can occur.

${ }^{22}$ For a literature on information-sharing among oligopolists, see Gal-Or $(1985,1986)$, in which rival firms have private information and use it against one another.

${ }^{23}$ Lizzeri (1999) discusses the strategic manipulation of information by certification intermediaries and shows that a monopoly certification intermediary does not have full incentives to reveal all information. We assume away this 
The essence of this two-stage game is that each firm makes its first-stage disclosure decisions, considering the resulting consumers' beliefs about product qualities and price competition between firms in the second stage. We solve for a subgame-perfect Bayesian Nash equilibrium, which consists of firms' equilibrium disclosure and pricing strategies, and consumers' equilibrium purchasing decisions and beliefs about product qualities. Specifically, in the first stage each firm evaluates its payoff (profit) in the second stage under various information scenarios, which are determined by its own disclosure decisions and that of its rival. Then the firm chooses the optimal first-stage strategy that yields the best final payoff given consumers' beliefs and its rival's first-stage and second-stage responses. Consumers update their beliefs about firms' qualities using Bayes' rule after observing firms' disclosure decisions and then make purchasing decisions.

In section 2.3, we solve for the second stage outcomes. In section 2.4, we develop propositions regarding firms' prices and profits given firms' disclosure decisions and consumers' beliefs. In section 2.5, we solve the model and specify a Perfect Bayesian Equilibrium. We establish that firm $B$ has a dominant equilibrium disclosure strategy. However, firm $A$ 's equilibrium disclosure strategy critically hinges on the nature of consumer heterogeneity, i.e., on the values of $\beta, \lambda, \theta$, and $\Delta$.

\subsection{The Second-stage Outcomes Given Consumers' Beliefs}

We solve the second stage outcomes given firms' first stage disclosure decisions and consumers' beliefs about qualities of the two products. Recall that $\Delta=q_{h}-q_{l}$, i.e., $\Delta$ denotes the real difference between the high- and low-quality products. We also define $\tilde{\Delta} \equiv E_{\Omega}\left(Q_{B}\right)-E_{\Omega}\left(Q_{A}\right)$ as consumers' perceived difference in quality between the two products, given the disclosure regime, $\Omega$, where the range for $\tilde{\Delta}$ is $[-\Delta, \Delta]$, since either firm can produce a high-quality or low-quality product with equal probability.

To derive the demand functions for firms' products, we need to consider consumers' choices among three alternatives: purchase $Y_{A}$, purchase $Y_{B}$, or purchase neither and resort to the outside option. For consumer $i$ to participate in the market for product $A$ or $B$ instead of choosing the outside option, the

strategic effect and focus on firms' incentives to use a truthful and non-strategic certification mechanism. 
previously-defined market condition on her utility given in participation constraint in (3) must hold for one of these products. Whether this participation constraint is satisfied for some or all consumers depends on consumers' perception of product quality. There are three potential situations can arise, depending on consumers' perceptions of the quality of these products. The first situation arises when either or both products are perceived by consumers to be of quality $q_{l}$. Given the availability of the outside option, no quality-lovers will be willing to purchase a product revealed to be of quality $q_{l}$ and the firm selling it will generate all its profit from the quality-satisficers' market. Note that if one product is perceived to be of quality $q_{l}$ while the rival product is perceived to be of a quality higher than $q_{l}$, the rival firm will enjoy a monopoly profit in the quality-lovers' market. The second situation arises when either or both products are perceived to be of quality greater than $q_{l}$ to draw a positive number of consumers into both markets but not high enough so that the two firms need not directly compete with each other in one or both consumer markets. Finally, the third situation occurs when the perceived qualities of both products are sufficiently high so that the market participation condition in (3) holds for all consumers. As a result, the two firms always engage in head-to-head competition. Since the third situation captures the essence of strategic interaction by firms trying to balance tradeoffs in two segmented consumer markets, we start from solving the pricing equilibrium conditioning on $\tilde{\Delta}$ in this scenario, and then work our way back to see what will happen when perceived qualities are lower and firms may not directly compete with each other in one or both of the consumer markets.

If the two firms directly compete with each other in the markets for both quality-satisficers and quality-lovers, the purchase decisions of the two types of consumers can be characterized as follows:

- If a consumer is a quality-satisficer, she will purchase firm $A$ 's product $Y_{A}=Y\left(0, Q_{A}\right)$ if and only if $X_{i}$ $\leq \frac{P_{B}-P_{A}+\lambda}{2 \lambda}$ and firm $B$ 's product $Y_{B}=Y\left(1, Q_{B}\right)$ if and only if $X_{i}>\frac{P_{B}-P_{A}+\lambda}{2 \lambda}$.

- If a consumer is a quality-lover, she will purchase $Y_{A}$ if and only if $X_{i} \leq \frac{P_{B}-P_{A}+\lambda-\theta \tilde{\Delta}}{2 \lambda}$ and $Y_{B}$ if 
and only if $X_{i}>\frac{P_{B}-P_{A}+\lambda-\theta \tilde{\Delta}}{2 \lambda}$.

These purchase decisions are illustrated in Figure 2. In the figure, the horizontal axis represents the location of consumers, while the vertical axis represents the probability that a quality-lover lives at location $X$. The positively-sloped line in the figure divides the $(X, \operatorname{Pr}(\theta))$ space into two areas: area $C_{1}+C_{4}$, which characterizes the "location regions" for quality-lovers, and area $C_{2}+C_{3}$, which characterizes the corresponding regions for quality-satisficers. This figure illustrates the situation in which a larger mass of quality-lovers reside closer to firm $B$ than firm $A$.

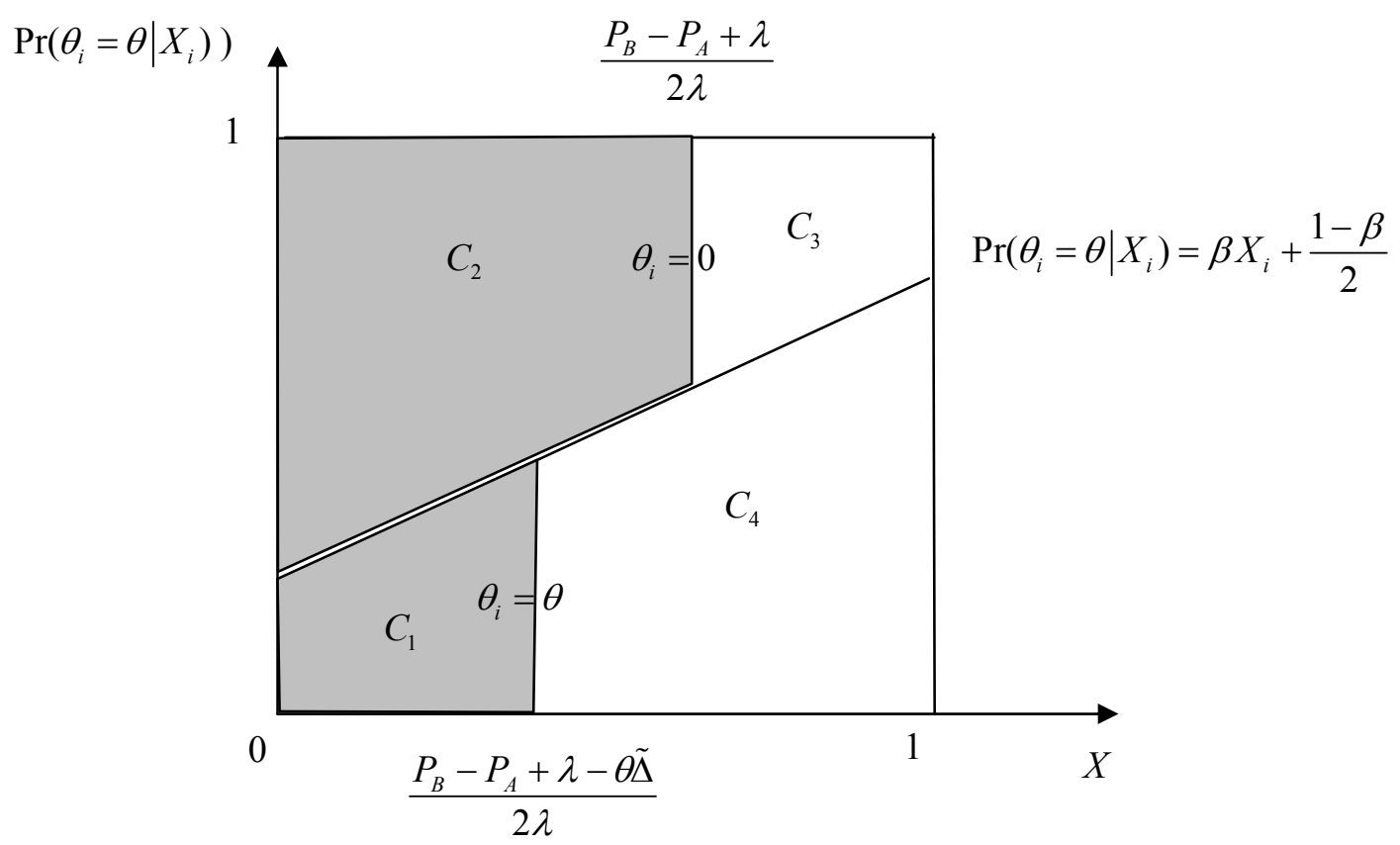

Figure 2: Consumers' Purchase Decisions

We denote area $C_{1}+C_{2}$ by $s_{A}$, which is the proportion of consumers buying product $Y_{A}$, i.e., the market share for product $Y_{A}$ and area $C_{3}+C_{4}$ by $s_{B}$, which is the market share for product $Y_{B}$. Algebraically, these market shares are given by: 


$$
\begin{aligned}
s_{A}= & \operatorname{area}\left(C_{1}\right)+\operatorname{area}\left(C_{2}\right) \\
= & \frac{1}{2}\left(\frac{1-\beta}{2}+\beta \frac{P_{B}-P_{A}+\lambda-\theta \tilde{\Delta}}{2 \lambda}+\frac{1-\beta}{2}\right)\left(\frac{P_{B}-P_{A}+\lambda-\theta \tilde{\Delta}}{2 \lambda}\right) \\
& +\frac{1}{2}\left(1-\frac{1-\beta}{2}+1-\beta \frac{P_{B}-P_{A}+\lambda}{2 \lambda}-\frac{1-\beta}{2}\right)\left(\frac{P_{B}-P_{A}+\lambda}{2 \lambda}\right) \\
= & \left(1-\frac{\beta \theta \tilde{\Delta}}{2 \lambda}\right)\left(\frac{P_{B}-P_{A}+\lambda}{2 \lambda}\right)+\frac{\beta \theta^{2} \tilde{\Delta}^{2}}{8 \lambda^{2}}-(1-\beta) \frac{\theta \tilde{\Delta}}{4 \lambda} \\
S_{B} & =\operatorname{area}\left(C_{3}\right)+\operatorname{area}\left(C_{4}\right)=1-s_{A} \\
& =1-\left(1-\frac{\beta \theta \tilde{\Delta}}{2 \lambda}\right)\left(\frac{P_{B}-P_{A}+\lambda}{2 \lambda}\right)-\frac{\beta \theta^{2} \tilde{\Delta}^{2}}{8 \lambda^{2}}+(1-\beta) \frac{\theta \tilde{\Delta}}{4 \lambda}
\end{aligned}
$$

The profit functions are given by: ${ }^{24}$

$$
\begin{aligned}
& \pi_{A}=P_{A} s_{A} \\
& \pi_{B}=P_{B} s_{B}
\end{aligned}
$$

To ensure that there are maximal values of profit functions, that prices are strategically complementary, and that there is a unique and stable price equilibrium, we assume that $\theta \Delta<\lambda$. This assumption ensures that the profit functions are well defined. The following first-order conditions characterize the firms' profit maximizing problems:

$$
\begin{aligned}
& S_{A}-P_{A}\left[\frac{1-\frac{\beta \theta \tilde{\Delta}}{2 \lambda}}{2 \lambda}\right]=0 \\
& S_{B}-P_{B}\left[\frac{1-\frac{\beta \theta \tilde{\Delta}}{2 \lambda}}{2 \lambda}\right]=0
\end{aligned}
$$

The conditions in (10) and (11) imply the following best-response functions:

$$
\begin{aligned}
& P_{A}^{B R}=\frac{1}{2}\left(P_{B}+\lambda+\frac{\beta \theta^{2} \tilde{\Delta}^{2}-2 \lambda(1-\beta) \theta \tilde{\Delta}}{4 \lambda-2 \beta \theta \tilde{\Delta}}\right)=\frac{1}{2}\left(P_{B}+\lambda-\frac{1}{2} \theta \tilde{\Delta}(1-\tilde{\omega})\right) \\
& P_{B}^{B R}=\frac{1}{2}\left(P_{A}+\lambda-\frac{\beta \theta^{2} \theta \tilde{\Delta}^{2}-2 \lambda(1+\beta) \theta \tilde{\Delta}}{4 \lambda-2 \beta \theta \tilde{\Delta}}\right)=\frac{1}{2}\left(P_{A}+\lambda+\frac{1}{2} \theta \tilde{\Delta}(1+\tilde{\omega})\right),
\end{aligned}
$$

where $\tilde{\omega}=\frac{2 \lambda \beta}{2 \lambda-\beta \theta \tilde{\Delta}}$. The equilibrium prices for the two products are given by: 


$$
\begin{aligned}
& P_{A}^{*}=\lambda+\frac{\theta \tilde{\Delta}}{6}\left(\frac{6 \lambda \beta-(2 \lambda-\beta \theta \tilde{\Delta})}{2 \lambda-\beta \theta \tilde{\Delta}}\right)=\lambda+\frac{\theta \tilde{\Delta}}{2}\left(\tilde{\omega}-\frac{1}{3}\right) \\
& P_{B}^{*}=\lambda+\frac{\theta \tilde{\Delta}}{6}\left(\frac{6 \lambda \beta+(2 \lambda-\beta \theta \tilde{\Delta})}{2 \lambda-\beta \theta \tilde{\Delta}}\right)=\lambda+\frac{\theta \tilde{\Delta}}{2}\left(\tilde{\omega}+\frac{1}{3}\right) .
\end{aligned}
$$

It follows from (14) and (15) that:

$$
\begin{aligned}
& P_{A}^{*}+P_{B}^{*}=\frac{2 \lambda}{\beta} \tilde{\omega} \\
& P_{B}^{*}-P_{A}^{*}=\frac{\theta \tilde{\Delta}}{3} \cdot{ }^{25}
\end{aligned}
$$

The equilibrium profits of the two firms are:

$$
\begin{aligned}
& \Pi_{A}^{*}=P_{A}^{*} s_{A}^{*}=\frac{1}{2} \lambda\left[1+\frac{\theta \tilde{\Delta}}{2 \lambda}\left(\tilde{\omega}-\frac{1}{3}\right)\right]\left[1+\frac{\theta \tilde{\Delta}}{2 \lambda}\left(\frac{\beta \theta \tilde{\Delta}}{6 \lambda}-\frac{1}{3}\right)\right] \\
& \Pi_{B}^{*}=P_{B}^{*} s_{B}^{*}=\frac{1}{2} \lambda\left[1+\frac{\theta \tilde{\Delta}}{2 \lambda}\left(\tilde{\omega}+\frac{1}{3}\right)\right]\left[1-\frac{\theta \tilde{\Delta}}{2 \lambda}\left(\frac{\beta \theta \tilde{\Delta}}{6 \lambda}-\frac{1}{3}\right)\right]
\end{aligned}
$$

\subsection{Firms' Prices and Profits as Functions of $\tilde{\Delta}$}

The following propositions characterize how each firm's prices and profits depend on consumers' perceived quality of products $Y_{A}$ and $Y_{B}$.

\section{PROPOSITION 1:}

1) If product $j(j=A$ or $B)$ is perceived to be of low quality $\left(q_{l}\right)$, firm $j$ will earn a profit smaller than $\lambda / 2$.

2) If either firm becomes a local monopoly in one or both of the consumer markets, its total profit will be an increasing function of its perceived quality.

Proof: See the Appendix.

PROPOSITION 2: If the two firms engage in direct competition in the markets for both types of consumers, firm B's equilibrium price and profit in the second stage are strictly increasing functions of $\tilde{\Delta}$.

\footnotetext{
${ }^{24}$ Note that there are no production costs.

${ }^{25}$ Given this equilibrium price difference and our assumption $\theta \Delta<\lambda$, one can verify that there is full coverage in both the quality-satisficers' and quality-lovers' market.
} 
Proof: When firms $A$ and $B$ directly compete with each other in both consumer markets, consider how firm $B$ 's optimal pricing function varies with $\tilde{\Delta}$ :

$$
\begin{aligned}
\frac{\partial P_{B}^{*}}{\partial \tilde{\Delta}} & =\frac{\theta}{2}\left(\tilde{\omega}+\frac{1}{3}\right)+\frac{\theta \tilde{\Delta}}{2}\left(\frac{\partial \tilde{\omega}}{\partial \tilde{\Delta}}\right)=\frac{\theta}{2}\left(\tilde{\omega}+\frac{1}{3}\right)+\frac{\theta \tilde{\Delta}}{2} \frac{2 \lambda \beta^{2} \theta}{(2 \lambda-\beta \theta \tilde{\Delta})^{2}} \\
& =\frac{\theta}{2} \tilde{\omega}+\frac{\theta}{6}+\frac{\theta^{2} \tilde{\Delta}}{4 \lambda} \tilde{\omega}^{2}=\frac{\theta}{2} \tilde{\omega}\left(1+\frac{\theta \tilde{\Delta}}{2 \lambda} \tilde{\omega}\right)+\frac{\theta}{6} \\
& =\frac{\theta}{2 \beta} \tilde{\omega}^{2}+\frac{\theta}{6}=\frac{\theta}{2}\left(\frac{4 \lambda^{2} \beta}{(2 \lambda-\beta \theta \tilde{\Delta})^{2}}+\frac{1}{3}\right)
\end{aligned}
$$

We can show $\frac{\partial P_{B}^{*}}{\partial \tilde{\Delta}}>0$ because $\theta>0, \lambda>0, \beta \geq 0$, and $2 \lambda-\beta \theta \tilde{\Delta}>0$. The last inequality holds because 0 $\leq \beta \leq 1, \theta \Delta<\lambda$, and $-\Delta \leq \tilde{\Delta} \leq \Delta$.

Now consider how firm $B$ 's profits varies with $\tilde{\Delta}$ :

$$
\begin{aligned}
\frac{\partial \Pi_{B}^{*}}{\partial \tilde{\Delta}} & =\frac{\partial P_{B}^{*}}{\partial \tilde{\Delta}} s_{B}^{*}+P_{B}^{*} \frac{\partial s_{B}^{*}}{\partial \tilde{\Delta}} \\
& =\frac{\partial P_{B}^{*}}{\partial \tilde{\Delta}} s_{B}^{*}+P_{B}^{*}\left[\frac{\theta}{4 \lambda}\left(-\frac{\beta \theta \tilde{\Delta}}{6 \lambda}+\frac{1}{3}\right)-\frac{\theta \tilde{\Delta}}{4 \lambda} \frac{\beta \theta}{6 \lambda}\right] . \\
& =\frac{\partial P_{B}^{*}}{\partial \tilde{\Delta}} S_{B}^{*}+P_{B}^{*} \frac{\theta}{12 \lambda^{2}}(\lambda-\beta \theta \tilde{\Delta})
\end{aligned}
$$

We can show $\frac{\partial \Pi_{B}^{*}}{\partial \tilde{\Delta}}>0$ because $\frac{\partial P_{B}^{*}}{\partial \tilde{\Delta}}>0, s_{B}^{*}>0, P_{B}^{*}>0, \theta>0, \lambda>0$, and $\lambda-\beta \theta \tilde{\Delta} \geq 0 . \quad$ Q.E.D.

PROPOSITION 3: If product $Y_{B}$ is perceived to be of high quality $\left(q_{h}\right)$, there exists a cutoff value $\beta^{*} \in$ $(0,1)$, such that when $\beta>\beta^{*}$, firm A's equilibrium price in the second stage is higher if the perceived quality of its product is the average quality, $\left(q_{h}+q_{l}\right) / 2$, than if the quality of its product is perceived to be of high quality $\left(q_{h}\right)$.

Proof: When product $A$ is perceived to be of high quality $\left(q_{h}\right)$, firm $A$ will charge a price of $P_{A}^{q_{h}}=\lambda$. When product $A$ is perceived to be of average quality, $\left(q_{h}+q_{l}\right) / 2$, firm $A$ will charge a price of $P_{A}^{q_{a}}=$ $\lambda+\frac{\theta \tilde{\Delta}}{2}\left(\tilde{\omega}-\frac{1}{3}\right)$. If $\tilde{\omega}>\frac{1}{3}$, or equivalently, $\beta>\beta^{*}=\frac{2 \lambda}{6 \lambda+\theta \tilde{\Delta}}$, we have $P_{A}^{q_{a}}>P_{A}^{q_{h}}$. We can show that 
$0<\beta^{*}=\frac{2 \lambda}{6 \lambda+\theta \tilde{\Delta}}<1$ because $0 \leq \tilde{\Delta} \leq \Delta$

PROPOSITION 4: If product $Y_{B}$ is perceived to be of high quality $\left(q_{h}\right)$, there exists a cutoff value $\beta^{* *} \in$ $(0,1)$, such that when $\beta>\beta^{* *}$, firm A's equilibrium profit in the second stage is higher if the perceived quality of its product is the average quality, $\left(q_{h}+q_{l}\right) / 2$, than if the quality of it's product is perceived to be of high quality $\left(q_{h}\right)$.

Proof: When product $A$ is perceived to be of high quality $\left(q_{h}\right)$, firm $A$ will receive a profit of $\pi_{A}^{q_{h}}=\lambda / 2$. When product $A$ is perceived to be of average quality, $\left(q_{h}+q_{l}\right) / 2$, firm $A$ will receive a profit of $\Pi_{A}^{q_{a}}=\frac{1}{2} \lambda\left[1+\frac{\theta \tilde{\Delta}}{2 \lambda}\left(\tilde{\omega}-\frac{1}{3}\right)\right]\left[1+\frac{\theta \tilde{\Delta}}{2 \lambda}\left(\frac{\beta \theta \tilde{\Delta}}{6 \lambda}-\frac{1}{3}\right)\right]$. We can prove that $\frac{\partial \Pi_{A}^{q_{a}}}{\partial \beta}>0$. (See the Appendix.) When $\beta=0, \Pi_{A}^{q_{a}}=\frac{1}{2} \lambda\left(1-\frac{\theta \tilde{\Delta}}{6 \lambda}\right)^{2}<\frac{1}{2} \lambda$ because $0<\theta \tilde{\Delta}<\lambda$. When $\beta=1$, we can show:

$$
\begin{aligned}
\Pi_{A}^{q_{a}} & =\frac{1}{2} \lambda\left[1+\frac{\theta \tilde{\Delta}}{2 \lambda}\left(\frac{2 \lambda}{2 \lambda-\theta \tilde{\Delta}}-\frac{1}{3}\right)\right]\left[1+\frac{\theta \tilde{\Delta}}{2 \lambda}\left(\frac{\beta \theta \tilde{\Delta}}{6 \lambda}-\frac{1}{3}\right)\right] \\
& >\frac{1}{2} \lambda\left[1+\frac{\theta \tilde{\Delta}}{2 \lambda}\left(\frac{2}{3}\right)\right]\left[1+\frac{\theta \tilde{\Delta}}{2 \lambda}\left(-\frac{1}{3}\right)\right] \\
& =\frac{1}{2} \lambda\left(1+\frac{\theta \tilde{\Delta}}{3 \lambda}\right)\left(1-\frac{\theta \tilde{\Delta}}{6 \lambda}\right)=\frac{1}{2} \lambda\left[1+\frac{\theta \tilde{\Delta}}{12 \lambda}-\frac{\theta \tilde{\Delta}}{18 \lambda}\right]>\frac{1}{2} \lambda
\end{aligned}
$$

Because $\frac{\partial \Pi_{A}^{q_{a}}}{\partial \beta}>0$, there must exist a $\beta^{* *} \in(0,1)$, such that when $\beta>\beta^{* *}, \Pi_{A}^{q_{a}}>\lambda / 2$.

Q.E.D.

The above propositions characterize how the firms' prices and profits vary as a function of what consumers perceive about the quality of their products. Propositions 3 and 4, in particular, establish that if the degree of correlation between consumer preferences and locations, $\beta$, is sufficiently high and one of the firm has a high quality product, then the equilibrium profit and price of the other product will be higher when it is perceived quality equals the average relative to if it is perceived as being a high quality product. As $\beta$ approaches 1 and consumers are more geographically similar in their tastes, anything that reduces the differentiation between the two products will result in more intense price competition and, in 
turn, cause the prices and profits of firm $A$ to fall. To better understand these properties, consider how the firms' best-response functions in a fully-covered market vary with the degree to which consumers are geographically segregated by tastes. When $\beta=0$, the best-response functions are:

$$
\begin{aligned}
& P_{A}^{B R, \beta=0}=\frac{1}{2}\left[P_{B}+\lambda-\frac{1}{2} \theta \tilde{\Delta}\right] \\
& P_{B}^{B R, \beta=0}=\frac{1}{2}\left[P_{A}+\lambda+\frac{1}{2} \theta \tilde{\Delta}\right]
\end{aligned}
$$

When $\beta=1$, the best-response functions are:

$$
\begin{aligned}
& P_{A}^{B R, \beta=1}=\frac{1}{2}\left[P_{B}+\lambda-\frac{1}{2} \theta \tilde{\Delta}\left(1-\frac{2 \lambda}{2 \lambda-\theta \tilde{\Delta}}\right)\right] \\
& P_{B}^{B R, \beta=1}=\frac{1}{2}\left[P_{A}+\lambda+\frac{1}{2} \theta \tilde{\Delta}\left(1+\frac{2 \lambda}{2 \lambda-\theta \tilde{\Delta}}\right)\right]
\end{aligned}
$$

In the general case, the best-response functions are a weighted average of those given in (18) - (21):

$$
\begin{aligned}
& P_{A}^{B R}=\alpha P_{A}^{B R, \beta=0}+(1-\alpha) P_{A}^{B R, \beta=1} \\
& P_{B}^{B R}=\alpha P_{B}^{B R, \beta=0}+(1-\alpha) P_{B}^{B R, \beta=1},
\end{aligned}
$$

where $\alpha=1-\beta \frac{2 \lambda-\theta \tilde{\Delta}}{2 \lambda-\beta \theta \tilde{\Delta}}$ and $\alpha \in[0,1] .^{26}$

Figure 3 illustrates the above decomposition of firms' best-response functions when $\tilde{\Delta} \geq 0$, that is, when consumers perceive that the quality of product $Y_{B}$ is higher than or equal to that of product $Y_{A}{ }^{27}$ In this figure, the intersection of $P_{A}^{B R}$ and $P_{B}^{B R}$ is the price equilibrium. The decomposition shows that all points along the bold line $L H$ can be supported as an equilibrium, given that $\alpha \in[0,1] .{ }^{28}$ Which equilib-

${ }^{26}$ Note that $\frac{\partial \alpha}{\partial \beta}=-\frac{2 \lambda(2 \lambda-\theta \tilde{\Delta})}{(2 \lambda-\beta \theta \tilde{\Delta})^{2}}<0$. When $\beta=0, \alpha=1$ and when $\beta=1, \alpha=0$. Therefore, $\alpha \in[0,1]$.

${ }^{27}$ The intuition conveyed by Figure 3 is similar to that for the results in Corts (1998), who investigates how price discrimination may lead to an all-worse-off result for firms ranking consumer groups differently.

${ }^{28}$ We have established that $P_{B}^{*}-P_{A}^{*}=\theta \tilde{\Delta} / 3$. It follows that all price equilibria form a straight line that is independent of $\beta$. Any point on this line is a weighted average of two end points. 
rium will be realized depends on $\beta$. If, for example, $\beta=1$ (corresponding to $\alpha=0$ ), the equilibrium will be at point $H$ (the northeast corner of line $L H$ ). If $\beta=0$ (corresponding to $\alpha=1$ ), the equilibrium will be at point $L$ (the southwest corner of line $L H$ ).

Point $M$ in Figure 3 is the intersection of best response functions and the price equilibrium where consumers perceive the two products to be of the same quality, i.e., $\tilde{\Delta}=0$. When consumers perceive that product $Y_{B}$ is of higher quality than $Y_{A}$, the best response function of firm $B$ will always shift upward. The magnitude of this upward shift depends on $\beta, \lambda, \theta$, and $\tilde{\Delta}$. The larger is $\beta$, the greater is the magnitude of the shift. At the same time, firm $A$ 's best response function first shifts downward and then shifts upward as $\beta$ reaches a certain threshold. As shown in the figure, the region close to point $H$ on line $L H$ corresponds to the situation where not only firm $B$, but also firm $A$, is able to charge a higher price when product $Y_{B}$ is perceived to be of higher quality than is product $Y_{A}$. Suppose consumers already perceive product $Y_{B}$ as a high-quality product. When $\beta$ is sufficiently large so as to be close to point $H$ on line $L H$ in Figure 3, both firms would have to lower their prices if product $Y_{A}$ is perceived to be a high-quality, rather than a low-quality, product. How would this price competition affect firm $A$ 's disclosure incentive? Section 2.5 provides an answer. 


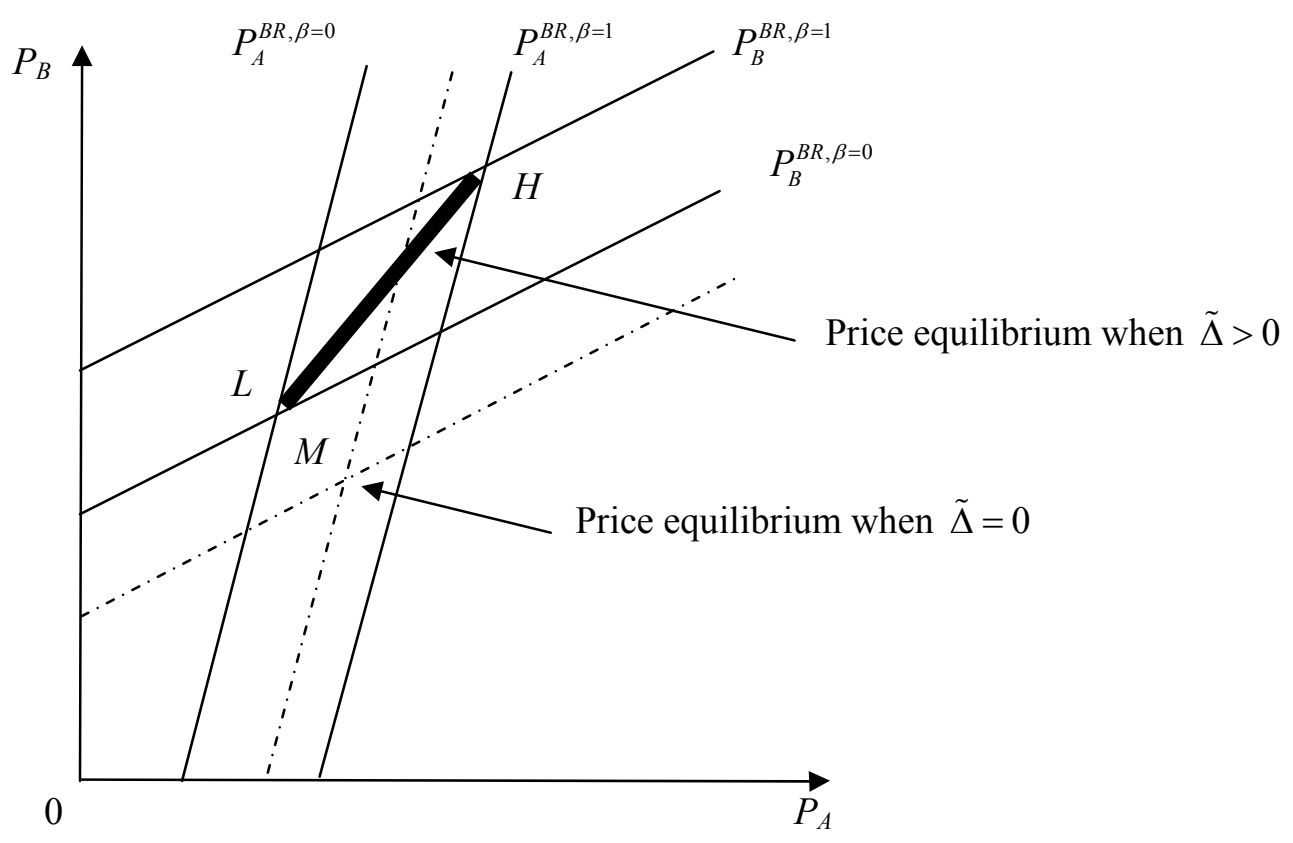

Figure 3: Price Equilibria

\subsection{A Perfect Bayesian Equilibrium of Incomplete Disclosure}

We now establish the main result of the paper concerning when partial disclosure occurs.

Proposition 5: There exists a cutoff value for $\beta, \beta^{* *} \in(0,1)$, such that if $\beta>\beta^{* *}$, information disclosure is incomplete in a Perfect Bayesian Equilibrium of the duopoly game. In this equilibrium:

1) Firm B always discloses its quality if it produces a high-quality product. If firm B does not disclose the quality of its product, consumers correctly infer that it produces a low-quality product.

2) If firm B produces (and discloses) a high-quality product, firm A always chooses not to disclose the quality of its product, even if it produces a high-quality product. Only if firm B produces a lowquality product will firm A choose to disclose that the quality of its product is high.

3) If firm B produces (and discloses) a high-quality product, consumers will maintain their perception of the quality of product $Y_{A}$ as $E_{\Omega=\varnothing}\left(Q_{A}\right)=\left(q_{h}+q_{l}\right) / 2$ and perceive the quality difference between the two products to $\tilde{\Delta}^{*}=E_{\Omega=\varnothing}\left(Q_{B}\right)-E_{\Omega=\varnothing}\left(Q_{A}\right)=\Delta / 2$. If firm B produces a low-quality product, consumers correctly infer that non-disclosure by firm A means that it produces a low-quality product. 
4) The equilibrium prices are given by (14) and (15), and the equilibrium profits are given by (16) and (17), with $\tilde{\Delta}^{*}$ substituted in for $\tilde{\Delta}$.

Proof: We consider each of the components of Proposition 5 in turn.

1) Propositions 1 and 2 has established: a) firm $B$ 's profit is an increasing function of its expected quality if it does not engage in direct competition with firm $A$ in both markets; c) firm $B$ 's equilibrium profit function in the second stage is strictly increasing in $\tilde{\Delta}$ when firm $A$ and $B$ are engaging in direct competition in both consumer markets. By disclosing its product to be of high quality, firm $B$ can maximize consumers' perception of its product quality $E\left(Q_{B}\right)$ and thus $\tilde{\Delta}$. So firm $B$ 's dominant strategy, if it produces a high-quality product, is disclosure. It is straightforward to establish that consumers associate low quality with undisclosed product $Y_{B}$ because firm $B$ has a dominant strategy to disclose its high quality.

2) There are two cases to consider with respect to firm $A$ 's disclosure decision:

a) If firm $B$ produces (and discloses) a high-quality product, firm $A$ will earn a profit less than $\lambda / 2$ if it is perceived to produce low quality $\left(q_{l}\right)$ (established in Proposition 1) and a profit equal to $\lambda / 2$ if it is perceived to produce high quality $\left(q_{h}\right)$ (established by equation $(15)$ with $\tilde{\Delta}=0$ ). Proposition 4 establishes that when $\beta>\beta^{* *} \in(0,1)$, firm $A$ 's second-stage equilibrium profit is higher if it is perceived to produce a product of average quality, $\left(q_{h}+q_{l}\right) / 2$, rather than one that is high-quality $\left(q_{h}\right)$. As a result, if firm $B$ produces (and discloses) a high-quality product, firm $A$ will not reveal the quality of its product, regardless of whether it is high- or low-quality whenever $\beta>\beta^{* *} \in$ $(0,1)$.

b) If firm $B$ produces (and is correctly perceived as producing) a low-quality product and firm $A$ produces a high-quality product, firm $A$ will receive a monopoly profit in the quality-lovers' market. Proposition 1 establishes that firm $A$ 's profit is increasing in $E\left(Q_{A}\right)$. Therefore, firm $A$ will choose disclosure if it produces a high-quality product.

3) Consumers update their beliefs using Bayes' rule based on what either firm does (or does not) dis- 
close about the quality of its product. Consumers associate low quality with undisclosed product $Y_{A}$ because firm $A$ 's dominant strategy is disclose its high quality if $Y_{B}$ is a low-quality product. However, if firm $B$ produces a high-quality product (and discloses that it is so), consumers gain no new information about product $Y_{A}$ because firm $A$ will not choose to disclose the quality of its product, regardless of whether it produced a high- or low-quality product. Consumers update as follows,

$$
\begin{aligned}
\operatorname{Pr}\left(Q_{A}=\right. & \left.q_{h} \mid A \text { : no disclosure }\right) \\
& =\frac{\operatorname{Pr}\left(A: \text { no disclosure } \mid Q_{A}=q_{h}\right) \operatorname{Pr}\left(Q_{A}=q_{h}\right)}{\operatorname{Pr}\left(A: \text { no disclosure } \mid Q_{A}=q_{h}\right) \operatorname{Pr}\left(Q_{A}=q_{h}\right)+\operatorname{Pr}\left(A: \text { no disclosure } \mid Q_{A}=q_{l}\right) \operatorname{Pr}\left(Q_{A}=q_{l}\right)} \\
& =\frac{\frac{1}{2}}{\frac{1}{2}+\left(1-\frac{1}{2}\right)}=\frac{1}{2},
\end{aligned}
$$

which implies that consumers will maintain their priors about the undisclosed quality of product $Y_{A}$.

4) With consumers' beliefs as specified in 3), neither firm will want to deviate from their strategies specified in 1) and 2). It is then straightforward to calculate the equilibrium prices and profits.

The above logic establishes that a Perfect Bayesian Equilibrium exists as either firm has its dominant disclosure and pricing strategy for a given set of parameter values and for consumers' Bayesian-updated beliefs. Under conditions specified in this proposition, information disclosure is incomplete in that firm $A$ will always choose not to disclose the quality of its product if firm $B$ produces and discloses that it's product is of high quality.

Q.E.D.

Proposition 5 makes clear that firms' disclosure incentives, as well as market outcomes under different information scenarios, critically hinges on consumer preferences and their distribution of consumer preferences over the two attributes of products, i.e., on the values of $\beta, \lambda, \theta$, and $\Delta$. It establishes that when $\beta<\beta^{* *}$, the unraveling result of Grossman and Milgrom holds, as either firm with a high-quality product will find it in their interest to disclose this fact. This can be seen in the limiting when $\beta=0$ and consumers' locations and tastes for quality are uncorrelated where non-disclosure allows either firm to improve their profits by non-disclosure. On the other hand, when $\beta>\beta^{* *}$, the unraveling process breaks 
down as firm $A$ has no incentive to disclose its quality when firm $B$ is perceived as producing a high quality product.

The equilibrium established in the above proposition is not unique. For example, if consumers believe that undisclosed quality is definitely the low quality, then firm $A$ has to disclose that its product is high quality for all values of $\beta$ to avoid losing all consumers and consumers' beliefs are therefore correct. In such an equilibrium, information disclosure is complete. However, the force of the proposition is to show that the unraveling process may break down under certain circumstances, i.e., that an incompletedisclosure equilibrium exists. Even without uniqueness of the equilibrium, the basic point remains that a firm with a low quality product may choose not to disclose its quality in order to alleviate competition with the outside option and that a firm with a high quality product also may choose not to disclose their quality in order to alleviate competition with the other high-quality firm. Put differently, Proposition 5 establishes that in the presence of products with multiple attributes and with consumers that have heterogeneous preferences over these attributes, an equilibrium exists in which voluntary disclosure of product quality by both sellers in the market will not be complete. Conceding that our equilibrium is not unique does not detract from what this paper established. Yes, there may be other equilibria in which voluntary disclosure occurs. But, our paper does establish that there exists an equilibrium in which it does not occur and we characterize, in part, some circumstances in which that is the case.

\section{Intuition and Extension}

As established in our model, the amount of information consumers have about the attributes of differentiated products affects their purchase decisions. Full information allows consumers to better assess the entire bundle of attributes contained in each product. However, allowing consumers to make such assessment, under certain circumstances, need not be in the best interest of firms. More information may change the substitutability of products and make consumers more sensitive to the prices charged by firms, which firms want to avoid. In this section, we provide intuition about the possibility of incomplete disclosure equilibrium by relating firms' strategic disclosure decisions to how disclosure can change the elasticities 
of demand for multi-attribute products.

\subsection{Product Substitution Patterns and Demand Elasticities}

Our results indicate that whether complete disclosure increases the price responsiveness of consumers for a product depends on how consumers' tastes for quality and their locations vis-à-vis firms are jointly distributed. To develop this relationship, we need to characterize the elasticities of demand for products $Y_{A}$ and $Y_{B}$. Consider first the demand elasticities for the two products under consumer beliefs $\tilde{\Delta}$. When market is fully covered, the demand elasticities for products $Y_{B}$ and $Y_{A}$ are given by:

$$
\begin{aligned}
e_{B} \equiv-\frac{\partial s_{B}}{\partial P_{B}} \frac{P_{B}}{s_{B}} & =\frac{\frac{P_{A}}{2 \lambda}\left(1-\frac{\beta \theta \tilde{\Delta}}{2 \lambda}\right)}{-\left(1-\frac{\beta \theta \tilde{\Delta}}{2 \lambda}\right)\left(\frac{P_{B}-P_{A}+\lambda}{2 \lambda}\right)-\frac{\beta \theta^{2} \tilde{\Delta}^{2}}{8 \lambda^{2}}+(1-\beta) \frac{\theta \tilde{\Delta}}{4 \lambda}} \\
& =\frac{P_{A}}{-\left(P_{B}-P_{A}+\lambda\right)-\frac{\theta \tilde{\Delta}}{2}(\tilde{\omega}-1)+\frac{2 \lambda \tilde{\omega}}{\beta}} \\
e_{A} \equiv-\frac{\partial s_{A}}{\partial P_{A}} \frac{P_{A}}{s_{A}} & =\frac{\frac{P_{A}}{2 \lambda}\left(1-\frac{\beta \theta \tilde{\Delta}}{2 \lambda}\right)}{\left(1-\frac{\beta \theta \tilde{\Delta}}{2 \lambda}\right)\left(\frac{\left.P_{B}-P_{A}+\lambda\right)}{2 \lambda}\right)+\frac{\beta \theta^{2} \tilde{\Delta}^{2}}{8 \lambda^{2}}-(1-\beta) \frac{\theta \tilde{\Delta}}{4 \lambda}} \\
& =\frac{P_{A}}{\left(P_{B}-P_{A}+\lambda\right)+\frac{\theta \tilde{\Delta}}{2}(\tilde{\omega}-1)}
\end{aligned}
$$

We can prove that $e_{B}$ is strictly decreasing in $\tilde{\Delta}$, i.e., $\frac{\partial e_{B}}{\partial \Delta}<0$. (See the Appendix for a proof.) We also can prove that $e_{A}$ is strictly decreasing in $\tilde{\Delta}$, i.e., $\frac{\partial e_{A}}{\partial \Delta}<0$, when $\beta$ is above a threshold in the range of $(0,1)$. (Again, see the Appendix.) It follows that when $\beta$ is large enough, price elasticities will increase for both firms as $\tilde{\Delta}$ decreases. Higher demand elasticities imply a greater degree of substitutability among products, which results in more intensive price competition among firms. As we have noted above, revelation of an attribute of a product to consumers that causes $\tilde{\Delta}$ to decrease will result in a decrease in prices and profits for both firms. As Proposition 5 establishes, a firm (in this case, firm $A$ ) will tend to 
find it in its interest to not disclose the unobserved attribute of its product in order to avoid inducing a reduction in $\tilde{\Delta}$, the perceived difference in the quality of the competing products. To do otherwise would induce greater price competition with its rival and, in the end, reduce its profits.

To reiterate our points on the difference between our work and Board (2009) in the introduction, we now show that our model is able to capture firms' incentives to strategically disclose information based the interaction between consumers' preferences over two different product dimensions. Note that as $\beta$ gets larger, consumers become more geographically segregated with respect to their tastes for quality. As a result, the "home" market for firm $B$ is mostly made up of quality-lovers, while the home market for firm $A$ consists of mostly quality-satisficers. Neither firm wants to disclose too low a quality for the fear to losing too much market share. However, if the market is fully covered and product $Y_{B}$ is perceived to be of higher quality than product $Y_{A}$, firms are properly "matched" to their home markets. Any effort to eliminate the perceived quality difference will upset this match and increase product substitutability. Firm $B$ will lose its dominance over quality-lovers while firm $A$ will lose out with quality-satisficers. Both firms will have to lower prices in order to win consumers back. In turn, firms may be reluctant to reveal too much information.

As is well known from the literature on optimal product differentiation, firms have strategic incentives to differentiate their products to reduce demand elasticities and alleviate price competition with rivals selling otherwise similar products. When the unobserved quality is the single dimension of product differentiation, disclosing information on product quality can precisely achieve the effect of differentiating a firm's own product away from that of its competitor. However, this is not true when there already exists another product attribute. In our model, from the perspective of consumers, both products are already fully differentiated by their locations, as the two firms are located at opposite ends of the Linear City. Even with no information about product quality, each firm already faces a downward sloping demand curve. Consumers do not view the two products as perfect substitutes and firms selling such differentiated products earn positive profits. With the existing horizontal differentiation, a firm's incentive to 
differentiate its product along another dimension via disclosure is not obvious and is strategically driven. Nothing concerning firms' proprietary information can be so readily "unraveling": a firm producing a product with a high-quality attribute may or may not reveal this attribute, depending on whether the revelation gives it the necessary "niche."

\subsection{Discussion: Extension to N Firms}

So far we have considered a duopoly model. How would this model be generalized to an $N$-firm case? We think that consumer heterogeneity combined with multi-attribute products can still result in less than complete disclosure of product quality. In a one-dimensional product attribute model, firms disclose their true quality level to achieve product differentiation. However, such disclosure may not be necessary if such differentiation already exists. Let's consider a Hotelling Linear City model with $N$ firms:

\begin{tabular}{llll}
\multicolumn{1}{l}{} & \multicolumn{1}{l}{ Firm 2 } & Firm 3 to Firm $N-1$ & Firm $N$
\end{tabular}

Suppose that in equilibrium all firms choose to disclose their true quality levels. Would any firm, say firm 1, have an incentive to deviate from this equilibrium, given the disclosure decisions of the other $N-1$ firms? For firm 1, the answer appears to hinge on the distribution of consumers' multi-dimensional preferences between products 1 and 2, which are the closest substitutes in the absence of any information about product quality. For example, if, in the absence of any disclosures, firm 2's "captive" clientele is mostly to be quality-lovers and if firm 2 discloses its product to be of high quality, then firm 1 may not choose to disclose its true quality level based on exactly the same logic as established in our simpler model. Therefore, it is not a Nash Equilibrium for all firms to disclose their qualities and, as a result, information will not be complete in this $N$-firm case. By the same token, firm 2's disclosure decision depends on the distribution of consumers' preferences between products 1 and 2 as well as between products 2 and 3. While solving for the equilibrium in this case will be more difficult given that consumer heterogeneity with respect to preferences over quality is more complicated, it still appears that the unraveling of information about product qualities need not always occur in the $\mathrm{N}$-firm case of our model. 


\section{Conclusion}

Effective provision of information ensures the efficiency of market operations and benefits social welfare in a variety of ways. Laws and regulations that make disclosure of information about products is one way to insure that consumers have such information. If, however, the "unraveling result" of Grossman (1981) and Milgrom (1981) holds, mandatory disclosure is unnecessary since firms have sufficient incentives voluntarily to disclose the quality of their products, so long as disclosure is verifiable and has trivial costs. As a result, we should not expect to see any systematic change in disclosure behaviors, prices, and profits of firms when disclosure mechanisms - either from voluntary to mandatory or visa-versa — change.

The findings in this paper cast doubt on the above characterization of the potential for non-market forces to ensure disclosure about product quality. In particular, we have shown that the unraveling result of Grossman and Milgrom can break down when products have more than one attribute and there is heterogeneity in consumer tastes over these attributes. We are able to show that firms do not always have full incentives voluntarily to disclose information on product quality as providing more information to consumers can cause more elastic demands and, thus, intensify price competition among firms. As a result, government intervention in the form of mandatory disclosure laws may change firm behavior and benefit consumers in markets with incomplete information. In fact, several recent empirical investigations of particular markets (Mathios, 2000; Jin and Leslie, 2003) has shown that mandatory disclosure laws do make a difference, indicating that firms selling differentiated products may gain financially from maintaining of "a culture of silence" with respect to the true quality of there products. ${ }^{29}$ More accurately, we show that mandatory disclosure laws may reduce prices in certain product markets as the resulting disclosure of information intensifies price competition. In principle, this latter implication is testable by examining how prices for certain products change before and after a change in a disclosure regime, such as the imposition of a law mandating the disclosure of quality attributes of a product.

\footnotetext{
${ }^{29}$ Jin and Leslie (2003) note: "One may wonder why restaurants did not disclose the results of their hygiene inspections prior to the grade cards. Why would a restaurant manager not create their own poster clearly showing their latest hygiene score, say, and display it in the window? Perhaps this indicates it is unprofitable for restaurants to increase the provision of hygiene quality information to consumers."
} 
More importantly, we find that what happens to prices, profits, and consumer welfare under different information scenarios depends on the distribution of consumer preferences over all of the attributes of products. In effect, disclosure of product quality by some firms can exert an "externality" effect on their rivals which can benefit consumers but make firms worse off. Without non-market forces, such as governments mandating disclosure, firms may find that their self-interest does not align with voluntary disclosure and consumers may find they lack critical information about product quality.

\section{References}

Anderson, S. and R. Renault (2006), “Comparative Advertising," mimeo, University of Virginia.

Becker, G. (1965), “A Theory of the Allocation of Time,” Economic Journal, Vol. 75, 493-517.

Board, O. (2009), "Competition and Disclosure," the Journal of Industrial Economics, Vol. LVII, 197213.

Cheong, I. and J. Y. Kim (2004), "Costly Information Disclosure in Oligopoly," the Journal of Industrial Economics, Vol. 52 (1), 121-132.

Corts, K. (1998), “Third-degree Price Discrimination in Oligopoly: All-out Competition and Strategic Commitment," Rand Journal of Economics, Vol. 29, 306-323.

Blau, D. and J. Currie (2006), "Preschool, Day Care and After-School Care: Who's Minding the Kids." In Handbook of the Economics of Education, Vol. 2, ed. Eric A. Hanushek and Finis Welch, 11631278. New York: Elsevier.

d'Aspremont, C., J. Gabszewicz, and J.-F. Thisse (1979), “On Hotelling's Stability in Competition,” Econometrica, 17(5): 1145-51.

Daughety, A. and J. Reinganum, (2008), “Communicating Quality: A Unified Model of Disclosure and Signaling," forthcoming, Rand Journal of Economics.

Dye, R.A. (1986), "Proprietary and Nonproprietary Disclosure," Journal of Business, Vol. 59, 331-366.

Dye, R. A. and S. S. Sridhar (1995), "Industry-wide Disclosure Dynamics," Journal of Accounting Research, Vol. 33, 157-174.

Gabszewicz, J. J. and J.-F. Thisse (1979), "Price Competition, Quality and Income Disparities," Journal of Economic Theory, 20: 340-359.

Grossman, S. (1981), "The informational Role of Warranties and Private Disclosure about Product Quality," Journal of Law and Economics, Vol. 24, 461-489.

Grossman, G. and C. Shapiro (1984), "Informative Advertising with Differentiated Products," Review of Economic Studies, Vol. 51, 63-82. 
Farrell, J. (1986), "Voluntary Disclosure: Robustness of the Unraveling Result, and Comments and Its Importance," Antitrust and Regulations, edited by Ronald E. Grieson, 91-103.

Fishman, M. and K. Hagerty (1997), "Mandatory Disclosure," the New Palgrave Dictionary of Economics and the Law, edited by Peter Newman, Macmillan Press.

Fishman, M. and K. Hagerty (2003), "Mandatory versus Voluntary Disclosure in Markets with Informed and Uninformed Customers," Journal of Law, Economics, and Organization, Vol. 19, 45-63.

Gallagher, T., A. Waterman, A. Ebers, V. Fraser, and W. Levinson, (2003), "Patients' and Physicians' Altitude Regarding the Disclosure of Medical Errors," Journal of American Medical Association, Vol. 289, No. 8.

Gal-Or, E. (1985), "Information Sharing in Oligopoly,” Econometrica, Vol. 53 (2), 329-344.

Gal-Or, E. (1986), "Information Transmission - Cournot and Bertrand Equilibrium," Review of Economic Studies, Vol. 53 (1), 85-92.

Gorman, W. (1980), “A Possible Procedure for Analyzing Quality Differentials in the Egg-Market,” Review of Economic Studies, Vol. 47, 843-259.

Hotelling, H. (1929), “Stability in Competition,” Economic Journal, 39(153): 41-57.

Hotz, V. J. and M. Xiao (2002), “Firms' Incentives to Disclose Information about Quality: The Case of Multi-Attribute Products with Heterogeneous Consumers", working paper, UCLA.

Jin, G. and P. Leslie (2003), "The Effects of Information on Product Quality: Evidence from Restaurants Hygiene Grade Cards," Quarterly Journal of Economics, Vol. 118, 409-451.

Jovanovic, B. (1982), “Truthful Disclosure of Information,” Bell Journal of Economics, Vol. 13, 36-44.

Lancaster, J. (1966), “A New Approach to Consumer Theory,” Journal of Political Economy, Vol. 74, 132-157.

Levin, D., J. Peck and L. Ye, (2009), "Quality Disclosure and Competition," the Journal of Industrial Economics, 57 (1), pp. 167-196.

Lizzeri, A. (1999), "Information Revelation and Certification Intermediaries," Rand Journal of Economics, Vol. 30 (2), 213-231.

Mathios, A.D. (2000), "The Impact of Mandatory Disclosure Laws on Product Choices: an Analysis of the Salad Dressing Market," Journal of Law and Economics, Vol. 43, 651-78.

Matthews, S. and A. Postlewaite (1985), "Quality Testing and Disclosure," RAND Journal of Economics, Vol. 16, 328-40.

Milgrom, P. (1981), “Good News and Bad News: Representation Theorems and Applications," Bell Journal of Economics, Vol. 12, 380-391.

Muth, R. (1966), "Household Production and Consumer Demand Functions," Econometrica, Vol. 34, 699-708.

Neven, D. (1985), “On Hotelling's Competition with Non-Uniform Customer Distributions,” Economic 
Letters, 21: 121-127.

Neven, D. and J.-F. Thisse (1990), "On Quality and Variety Competition," in Economic DecisionMaking: Games, Econometrics, and Optimization, J. J. Gabszewicz, J.-F. Richard and L. Wolsey, eds., Amsterdam: North-Holland, 175-199.

Okuno-Fujiwara, M., A. Postlewaite, and K. Suzumura (1990), "Strategic Information Revelation," Review of Economic Studies, Vol. 57, 25-47.

Peters, M. (1984), "Restrictions on Price Advertising," the Journal of Political Economy, Vol. 92, 472485.

Rosen, S. (1974), "Hedonic Prices and Implicit Markets: Product Differentiation in Pure Competition," Journal of Political Economy, Vol. 82, 34-55.

Shavell, S. (1994), "Acquisition and Disclosure of Information Prior to Sale," RAND Journal of Economics, Vol. 20, 183-95.

Simon, H. (1957), Models of Man, New York: John Wiley \& Son.

Stivers, A. (2004), "Unraveling of information: Competition and Uncertainty," the B.E. Journals: Topics in Theoretical Economics, 4(1).

Tirole, J. (1994), the Theory of Industrial Organization, Cambridge: MIT Press, 1994.

Verrecchia, R.E. (1983), "Discretionary Disclosure," Journal of Accounting and Economics, Vol. 5, 17994. 


\section{Appendix}

\section{A) Proof of Proposition 1.}

Proof: 1) If $E_{\Omega}\left(Q_{j}\right)=q_{l}$, firm $j$ will lose all quality-lovers and collect all its profit from the qualitysatisficers' market. Therefore firm $j$ 's market share is $s_{j} \leq 1 / 2$. The maximum price firm $j$ can charge is $V$, otherwise it will lose all quality-satisficers to either the outside option or the other firm. Because $V<\lambda$, firm $j$ 's profit will be less than $\lambda / 2$ if it is revealed as producing a low-quality product.

2) If one or both consumers markets are not fully covered by the two firms, either firm will become a local monopoly and do not directly compete with each other in the partially covered market. Either firm's profit is increasing with its perceived quality because it can always charge the same price and attract a larger market share in the market where it serves as a local monopoly unless it has already taken the entire market. Even with a full market share where it serves as a local monopoly, the firm can do no worse in profit because it can always charge the same price and receive the same market share.

Q.E.D.

B) Proof of $\frac{\partial \Pi_{A}^{q_{a}}}{\partial \beta}>0$ in Proposition 4:

Proof:

$$
\begin{aligned}
& \frac{\partial \Pi_{A}^{q_{a}}}{\partial \beta}=\frac{1}{2} \lambda\left[\frac{\theta \bar{\Delta}}{2 \lambda}\left(\frac{2 \lambda}{2 \lambda-\beta \theta \tilde{\Delta}}+\frac{2 \lambda \beta \theta \tilde{\Delta}}{(2 \lambda-\beta \theta \tilde{\Delta})^{2}}\right)\left[1+\frac{\theta \tilde{\Delta}}{2 \lambda}\left(\frac{\beta \theta \tilde{\Delta}}{6 \lambda}-\frac{1}{3}\right)\right]+\frac{\theta^{2} \tilde{\Delta}^{2}}{12 \lambda^{2}}\left[1+\frac{\theta \tilde{\Delta}}{2 \lambda}\left(\frac{2 \lambda \beta}{2 \lambda-\beta \theta \tilde{\Delta}}-\frac{1}{3}\right)\right]\right] \\
& =\frac{1}{2} \lambda\left[\frac{2 \lambda \theta \tilde{\Delta}}{(2 \lambda-\beta \theta \tilde{\Delta})^{2}}\left[1+\frac{\theta \tilde{\Delta}}{2 \lambda}\left(\frac{\beta \theta \tilde{\Delta}}{6 \lambda}-\frac{1}{3}\right)\right]+\frac{\theta^{2} \tilde{\Delta}^{2}}{12 \lambda^{2}}+\frac{\theta^{3} \tilde{\Delta}^{3}}{24 \lambda^{3}}\left(\frac{2 \lambda \beta}{2 \lambda-\beta \theta \tilde{\Delta}}-\frac{1}{3}\right)\right] \\
& =\frac{1}{2} \lambda\left[\frac{2 \lambda \theta \tilde{\Delta}}{(2 \lambda-\beta \theta \tilde{\Delta})^{2}}+\frac{2 \lambda \beta \theta^{3} \tilde{\Delta}^{3}}{12 \lambda^{2}(2 \lambda-\beta \theta \tilde{\Delta})^{2}}-\frac{\theta^{2} \tilde{\Delta}^{2}}{3(2 \lambda-\beta \theta \tilde{\Delta})^{2}}+\frac{\theta^{2} \tilde{\Delta}^{2}}{12 \lambda^{2}}+\frac{\beta \theta^{3} \tilde{\Delta}^{3}(2 \lambda-\beta \theta \tilde{\Delta})}{12 \lambda^{2}(2 \lambda-\beta \theta \tilde{\Delta})^{2}}-\frac{\theta^{3} \tilde{\Delta}^{3}}{72 \lambda^{3}}\right] \\
& =\frac{1}{2} \lambda\left[\frac{\theta \tilde{\Delta}(6 \lambda-\theta \tilde{\Delta})}{3(2 \lambda-\beta \theta \tilde{\Delta})^{2}}+\frac{\beta \theta^{3} \tilde{\Delta}^{3}(4 \lambda-\beta \theta \tilde{\Delta})}{12 \lambda^{2}(2 \lambda-\beta \theta \tilde{\Delta})^{2}}+\frac{\theta^{2} \tilde{\Delta}^{2}(6 \lambda-\theta \tilde{\Delta})}{72 \lambda^{2}}\right] \\
& \geq 0
\end{aligned}
$$

The inequality holds because $\lambda>0, \theta>0, \tilde{\Delta} \geq 0,0 \leq \beta \leq 1, \theta \Delta<\lambda$, and $\tilde{\Delta} \leq \Delta$ so that $6 \lambda-\theta \tilde{\Delta}>0$ and $4 \lambda-\beta \theta \tilde{\Delta}>0$.

Q.E.D. 
C) Proof of $\frac{\partial e_{B}}{\partial \tilde{\Delta}}<0$ in Section 3.1:

Proof:

$$
\begin{gathered}
\frac{\partial e_{B}}{\partial \tilde{\Delta}}=-\frac{P_{B}\left[-\frac{\theta}{2}\left(\frac{2 \lambda \beta}{2 \lambda-\beta \theta \tilde{\Delta}}-1\right)-\frac{\theta \tilde{\Delta}}{2} \frac{2 \lambda \beta^{2} \theta}{(2 \lambda-\beta \theta \tilde{\Delta})^{2}}+\frac{4 \lambda^{2} \beta \theta}{(2 \lambda-\beta \theta \tilde{\Delta})^{2}}\right]}{\left[-\left(P_{B}-P_{A}+\lambda\right)-\frac{\theta \tilde{\Delta}}{2}(\tilde{\omega}-1)+\frac{2 \lambda \tilde{\omega}]^{2}}{\beta}\right]} \\
=\frac{-P_{B} \frac{\theta}{2}\left[\frac{4 \lambda^{2} \beta}{(2 \lambda-\beta \theta \tilde{\Delta})^{2}}+1\right]}{\left[-\left(P_{B}-P_{A}+\lambda\right)-\frac{\theta \tilde{\Delta}}{2}(\tilde{\omega}-1)+\frac{2 \lambda \tilde{\omega}]^{2}}{\beta}\right]^{2}}<0
\end{gathered}
$$

The inequality holds because $\theta>0,0 \leq \beta \leq 1$, and $2 \lambda-\beta \theta \tilde{\Delta}>0$.

Q.E.D.

D) Proof of $\frac{\partial e_{A}}{\partial \tilde{\Delta}}<0$ when $\beta$ is large enough in Section 3.1:

Proof:

$$
\begin{gathered}
\frac{\partial e_{A}}{\partial \tilde{\Delta}}=-\frac{P_{A}\left[\frac{\theta}{2}\left(\frac{2 \lambda \beta}{2 \lambda-\beta \theta \tilde{\Delta}}-1\right)+\frac{\theta \tilde{\Delta}}{2} \frac{2 \lambda \beta^{2} \theta}{(2 \lambda-\beta \theta \tilde{\Delta})^{2}}\right]}{\left[\left(P_{B}-P_{A}+\lambda\right)+\frac{\theta \tilde{\Delta}}{2}(\tilde{\omega}-1)\right]^{2}} \\
=-\frac{P_{A} \frac{\theta}{2}\left[\left(\frac{4 \lambda^{2} \beta}{(2 \lambda-\beta \theta \tilde{\Delta})^{2}}-1\right)\right]}{\left[\left(P_{B}-P_{A}+\lambda\right)+\frac{\theta \tilde{\Delta}}{2}(\tilde{\omega}-1)\right]^{2}}
\end{gathered}
$$

We can easily show that when $\beta$ is above a threshold in the range of $(0,1), \frac{4 \lambda^{2} \beta}{(2 \lambda-\beta \theta \tilde{\Delta})^{2}}-1>0$ and thus $\frac{\partial e_{A}}{\partial \tilde{\Delta}}<0$

Q.E.D. 


\section{An Illustration of Our Model}

In this section, we illustrate how our results might play out with an example. ${ }^{30}$ Suppose there are two restaurants in a market, one is a fast food outlet specializing in hamburgers and the other is a French restaurant featuring fancy dishes like escargot. Two types of consumers-students and professors-populate this market. At the same price for a meal, we suppose that, on average, students strongly prefer hamburgers to French cuisine as eating fast food saves time for studying, while professors, who have more sophisticated palates, have just the opposite tastes. Meanwhile, professors also have higher hygiene standards than do students. ${ }^{31}$

Suppose the two restaurants may differ in their hygienic practices. Neither type of consumers, on their own, can readily determine the hygienic quality of the restaurants, although they have formed priors based on past experience. To reduce health risks, the local public health department inspects restaurants and rates their hygiene quality. Suppose that the department, based on its inspections, issues ratings of the hygiene quality to restaurants but that it is up to the restaurants as to whether they reveal to the general public their hygiene ratings. The inspections are unannounced and the inspectors rate the hygiene conditions on the day of inspection. Since hygiene conditions can vary over time, a more sanitary kitchen can sometimes fail to obtain certification and a usually dirty kitchen can sometimes pass an inspection.

Suppose, in fact, that the French restaurant maintains a very sanitary kitchen to cater to professors' standards, while the fast food restaurant's hygienic practices have larger variances. Let's first consider the case where both restaurants have a good day when inspected and receive high ratings. Let's presume that the French restaurant, with professors as its "captive" clientele, will be happy to announce its high rating. However, burger-loving students do not place value on better hygienic practices, at which the fast food outlet currently seems to excel. Will the fast food outlet want to post its high ratings?

\footnotetext{
${ }^{30}$ This example is inspired by Jin and Leslie (2003), who study the hygiene practices and sales volume of restaurants in Los Angeles County under alternative disclosure requirements concerning the findings of public health inspections.

${ }^{31}$ Professors, say, cannot afford to miss the classes they teach due to food poisoning while students do not mind missing a few of those classes, even if they have to spend the time in the student infirmary!
} 
Suppose the fast food restaurant does post its certificate. Naturally, some professors, who value French food less strongly than other professors, want to switch to the fast food outlet upon learning that it maintains more sanitary conditions. In response, the French restaurant may want to mark down the price it charges for a meal to lure back its consumer base. This move, however, will affect the fast food outlet's market share, as some students, who value hamburgers less strongly than other students, will be willing to switch to the French restaurant for cheaper meals. In turn, the fast food outlet also may want to reduce the price of its hamburgers, which may induce further price-cutting by the French restaurant. As a result of this price competition, both restaurants would end up with lower prices and profits if the fast food outlet were to post its hygiene ratings. Thus disclosing its hygiene rating would not be in the fast food outlet's self-interest. As a result, voluntary disclosure will not occur in this market, even though both professors and students may be better off by having information on hygiene quality—-for different reasons - prior to deciding where to dine.

What is central to this example is that consumers value both the horizontal attribute (taste of food or time saving) and a vertical attribute (hygiene quality) of the product (a meal outside the home) in a market in which buyer-seller sorting has resulted in a particular form of segregation of consumers. If consumers know both attributes of the meals each restaurant is serving, they will choose to trade-off their preferred meals for more sanitary food and need to be compensated for meals which they enjoy less. Under this configuration of consumer preferences, firms may not have an incentive to break the existing taste-segregation of consumers by disclosing information about one of the attributes of their meals. Disclosure may increase the substitutability between the two types of meals, intensify price competition, and lower profits for both restaurants. 